\title{
PHOTOGRAMMETRY AND MEDIEVAL ARCHITECTURE. USING BLACK AND WHITE ANALOGIC PHOTOGRAPHS FOR RECONSTRUCTING THE FOUNDATIONS OF THE LOST ROOD SCREEN AT SANTA CROCE, FLORENCE
}

\author{
F. Condorelli ${ }^{1 *}$, G. Pescarmona ${ }^{2}$, Y. Ricci ${ }^{3}$ \\ ${ }^{1}$ DAD, Department of Architecture and Design, Politecnico di Torino, Italy - francesca.condorelli@polito.it \\ ${ }^{2}$ SAGAS, Department of History, Archaeology, Geography, Art and Performing Arts, University of Florence, Italy - \\ giovanni.pescarmona@unifi.it \\ ${ }^{3}$ DIDA, Department of Architecture, University of Florence, Italy - ylenia.ricci@unifi.it
}

KEY WORDS: History of Medieval Art, Medieval Archaeology, Photogrammetry, Metric Quality Assessment, Digital Model, Virtual Reality

\begin{abstract}
:
In this research paper photogrammetric techniques have been successfully applied to historic black and white analogic photographs to convey previously inaccessible architectural and archaeological information. The chosen case study for this paper is the Franciscan Basilica of Santa Croce in Florence, Italy. A photogrammetric algorithm has been implemented over a series of $\mathrm{b} / \mathrm{w}$ negatives portraying the archaeological excavations carried out in the years 1967 - 1969, after the traumatic flood of the river Arno in 1966 that severely damaged the city centre of Florence and, particularly, the Santa Croce monumental site. The final aim of this operation is to provide solid evidence for the virtual reconstruction of the lost rood screen of the basilica of Santa Croce, the current subject of the PhD research of one of the Authors (Giovanni Pescarmona) at the University of Florence. The foundations that were uncovered during the archaeological excavation in the " $60 \mathrm{~s}$ are one of the most important hints towards a convincing retro-planning of the structure. Using advanced photogrammetric techniques, and combining them with LIDAR scanning, it is possible to uncover new datasets that were previously inaccessible for scholars, opening new paths of research. This interdisciplinary approach, combining traditional art-historical research methods and state-of-the-art computational tools, tries to bridge the gap between areas of research that still do not communicate enough with each other, defining new frameworks in the field of Digital Art History.
\end{abstract}

\section{HISTORICAL CONTEXT}

Over the past decades, Art Historians and Architectural Historians have shed light on the birth and the demise of rood screens in European churches, especially in buildings of the mendicant orders. These structures played a crucial role within medieval churches, as their main function was to separate the lower nave, destined to the laity, from the transept and the choir, reserved to the friars. Rood screens were also richly decorated and carved (Cooper 2017), boasting private chapels, altars, and sometimes two storeys, with the upper level working as a stage for preaching and sacred representations, held during religious festivities. Rood screens also provided exhibition spaces for painted panels, sculptures and mural paintings. The vast majority of the Italian rood screens have been torn down during the 16th century, as a result of profound changes in aesthetics and liturgy partially reflected by the dictates of the Council of Trent, which marked in western Europe the period known as the Catholic Counter-Reformation (Hall 1979). The scarcity of existing rood screens marks a lack of terms of comparison, making reconstructing the visual appearance and the structural quality of these lost structures a challenging and difficult task.

The rood screen at Santa Croce in Florence (called tramezzo in Italian 16th century sources) was an architectural partition structure spanning the entire width of the church, and was built in the fourth decade of the 14th century. Archival and documentary records tell us that the structure of the tramezzo was demolished in 1565 by Giorgio Vasari, one of the most prominent architects active in Florence in the second half of the 16th century, at the wish of Cosimo the I de Medici, Duke of Florence (Hall 1974).

Scholars possess a wealth of knowledge about the tramezzo in Santa Croce, making this an unusually well-documented context. A drawing on parchment in the State Archive of Florence has been identified as the project design for one of the chapels of the rood screen. This drawing is provided with a metric scale, showing the ancient florentine unit of the "arm" (corresponding to $58,36 \mathrm{~cm}$ ), which allows researchers to obtain measurements of the plan and the elevation of the structure.

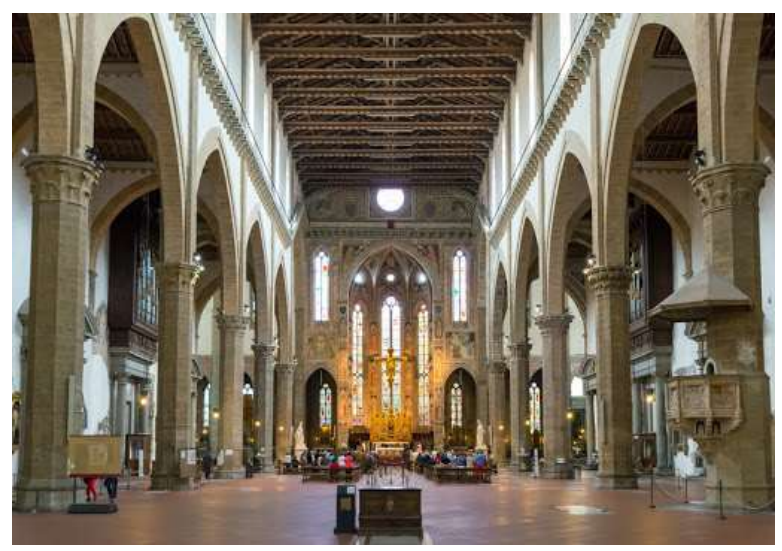

Figure 1. The basilica of Santa Croce, Florence.

\footnotetext{
$1 *$ Corresponding author
} 
Other existing elements in the church show clear signs of the structure of the tramezzo: among these are pilaster bases, mural paintings, and sculpted stone fragments. All these elements must be taken into account for the reconstruction phase, but an exhaustive analysis of all the available evidence falls beyond the scope of this paper.

A fundamental step for the retro-planning of the structure is to assess the position and the structural quality of its foundations (Verdiani, 2017). Being a continuous balcony made of masonry and limestone, spanning over 38 metres, and considerably high (at least 10 meters, including the gable and the vaults of the upper storey), the tramezzo was a heavy building, and must have been underpinned by solid groundworks. The foundations of the tramezzo were brought to light in 1967 , in the aftermath of the traumatic flood that caused severe damage to the built heritage of the city of Florence and hit violently the Santa Croce neighborhood, located in a natural depression adjacent to the riverside. Water and mud hit the basilica with striking violence and caused serious damage to artworks and architectures. The basilica was completely flooded; water and mud reached a height of 6 metres. After the emergency, when the water retired, an extensive excavation was carried out in the nave in order to remove the mud, restore the underground spaces, and rebuild the subterranean areas. These operations have been carried out quickly, to allow for the reopening of the church and the refurbishing of the pavement. As a consequence, not very much analytical material has been produced, and specifically we lack restoration reports.
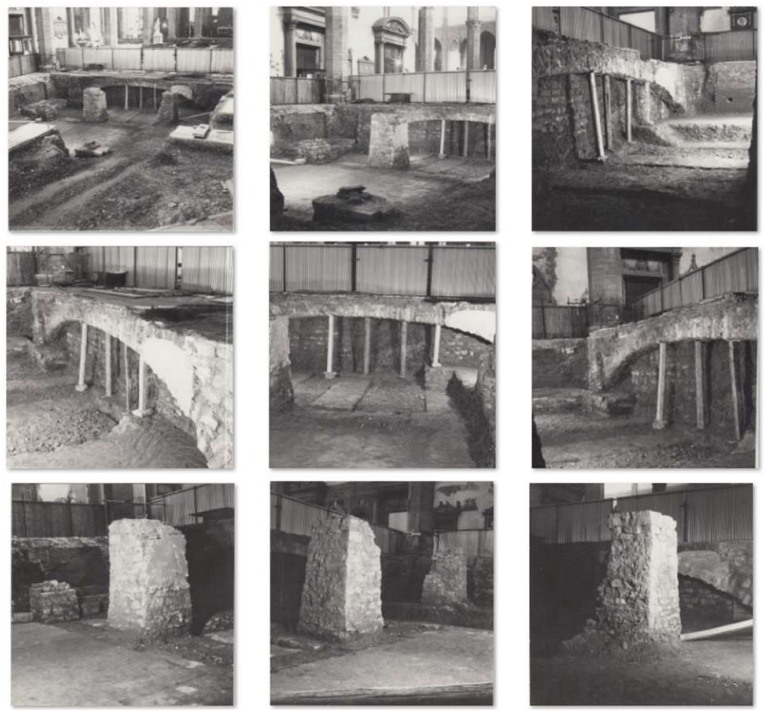

Figure 2. Selection of the historical b/w photographs of the excavations in the Basilica of Santa Croce in Florence that have been used for photogrammetric processing.

The most relevant documentation about these buried structures is a set of black and white photographs that have been made by the photographers in duty at the Soprintendenza (the institution responsible for the conservation of heritage in Italy) in the ' 60 , and that are stored nowadays in the Soprintendenza deposits in Florence, located in Pitti Palace. These images portray mainly the central nave of the church in different moments of the excavations from 1967 to 1972 . These photographs show masonry structures. Some portions of these structures are ruined; it is difficult to assess the dating of these damages, which could have been caused by modern excavations. In the central nave, between the fifth couple of pilasters, a wide transverse arch can be seen. This seems to be slightly slided towards the north side of the church, being not precisely aligned with the longitudinal axis of the nave. More towards the east, three pilasters in brickworks are visible. It is not known whether the restorers and architects who carried out the excavations in the " 60 knew the origin of these structures. Maria Hall (1974) convincingly identified these structures as the remaining foundations of the lost tramezzo, combining archival, visual, and archeological evidence.

During the excavations, these elements were also drawn on a 1:100 scale by architects from the Soprintendenza. Unfortunately, the foundation pilasters, as well as the transverse arch, have been demolished as a result of the renovation of the subterranean areas, and none of these constructions survives now. Therefore, the pictures taken during the operations and the survey drawings are the only reliable sources of information that we possess about the groundworks of the tramezzo.

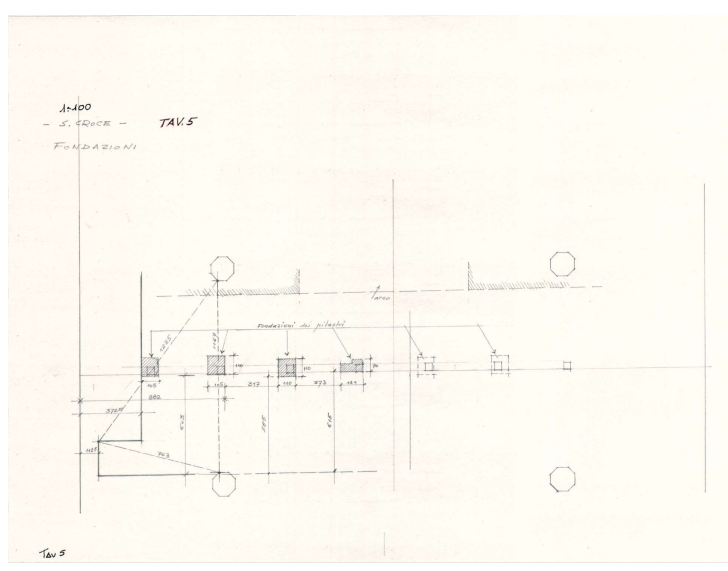

Figure 3. Plan drawing of the groundworks of the tramezzo (c. 1972).

The position of the foundations are crucial to determine the size and width of the tramezzo, as well as its arrangement within the nave. In fact, the two main reconstruction hypotheses of the tramezzo rely mainly on two different interpretations of the position, the number and the size of the groundworks. While Marcia Hall (1974) hypothesized a continuous series of 8 supports, underpinning 9 continuous bays, De Marchi (2011) proposed a different structure, more agile and permeable, supported by 6 pilasters, more concentrated in the central nave. Understanding the size and the location of these supports is therefore fundamental in order to successfully reconstruct the tramezzo.

\section{PHOTOGRAMMETRIC RECONSTRUCTION WORKFLOW}

A comprehensive set of digital data has been gathered in order to construct a solid reference system for the photogrammetric point cloud. Firstly, all the available material has been collected with the most accurate digital tools. A wide range of digital and analogic survey techniques have been used to gather all possible information on this context. GPR scans have been carried out, with negative results. The accessible underground areas have been extensively scanned with LIDAR technology.

Using portable scanners and plotters, drawings and photographs at the Soprintendenza have been digitised by the 
Florentine working unit, which results from the collaboration between the DIDA (Architecture) and SAGAS (History of Art) departments of the University of Florence. Both negatives and positives exist; however, for this research, only positives have been used, as negatives are very fragile, and are not accessible for scholars. In future phases of research, specific agreements could be made with the Soprintendenza for digitising negatives, obtaining images with better resolution allowing for a more precise alignment and a more accurate point cloud reconstruction.

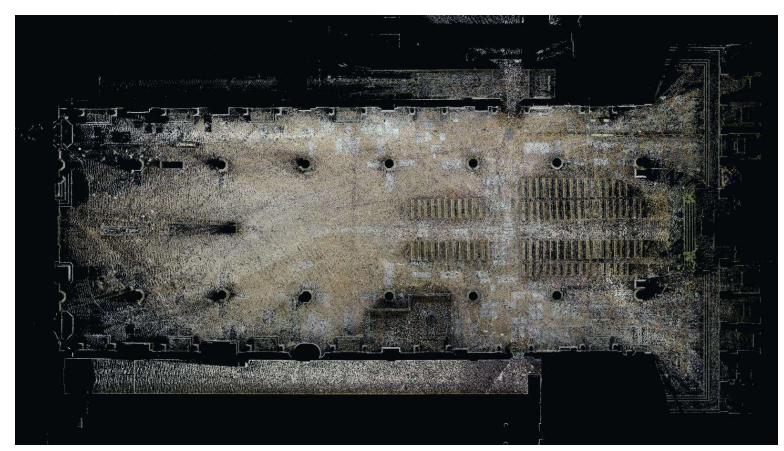

Figure 4. Three-dimensional point cloud of the central nave of the Basilica of Santa Croce, Florence.

Photogrammetry is a crucial step, and the only solution to obtain accurate metric information about the lost foundations. However, its implementation is technically challenging, since the available photographs are not optimised for photogrammetry: they overlap mildly, they have modest resolution, and lack colour. The dataset, in fact, consists of 12 black and white (1307x1303 pixel and 3.24 MB) and low resolution (even if acquired with high resolution scanner setting $600 \mathrm{dpi}$ ) images of the foundations (shown in Figure 2), with $40 \%$ of overlapping.

Referring to previous studies of the Author (Condorelli et al., 2019), a workflow is proposed to make the photogrammetric pipeline suitable for the processing of historical archival images.
The photogrammetric pipeline chosen as a reference in this workflow is the COLMAP (Schönberger et al., 2016) open source Structure-from-Motion and Multi-View Stereo (MVS) algorithm implementation, developed by ETH of Zurich, (COLMAP, Johannes L. Schoenberger, 2019).

A sketch of the entire workflow is presented in Figure 4 and is subdivided in two main phases, combining Structure-fromMotion (SfM) algorithms with Metric Quality Assessment, allowing for the final certification of the reconstruction. One of the risks of using photogrammetry on low-quality images is that the process cannot reconstruct all the parts of the building and that the final point cloud can be very sparse, due to the scarcity of information in the dataset. This could generate problems during the Metric Quality Assessment phase, such as the difficulty in the identification of useful points for the comparison with other point clouds, or the uncertainty in the extraction of known measures chosen as reference in the evaluation. Also, the absence or the scarcity of correspondence between the reconstructed point cloud and existing points of reference (Tazir et al., 2018) makes it difficult to scale the model and assess the metric quality of the 3D representation of lost heritage.

To solve these issues, several approaches have been proposed in previous studies: outlier filtering ( $\mathrm{Hu}$ et al., 2019), noise smoothing (Wang et al., 2013) and automatic filtering method, based on some geometric features computed on the sparse point cloud created in the bundle adjustment phase (Farella et al., 2019). These studies focused mostly on finding automatic solutions to the problem.

In order to optimize this standard pipeline, a complementary step (highlighted in red in Figure 4) has been included, with the aim of manually selecting specific Feature Points before the matching phase (method developed in Condorelli et al., 2019). This step was implemented to guarantee a sufficient number of points for the metric evaluation of the final point cloud.

The details of this new step are shown in Figure 6 and consists in the following phases:

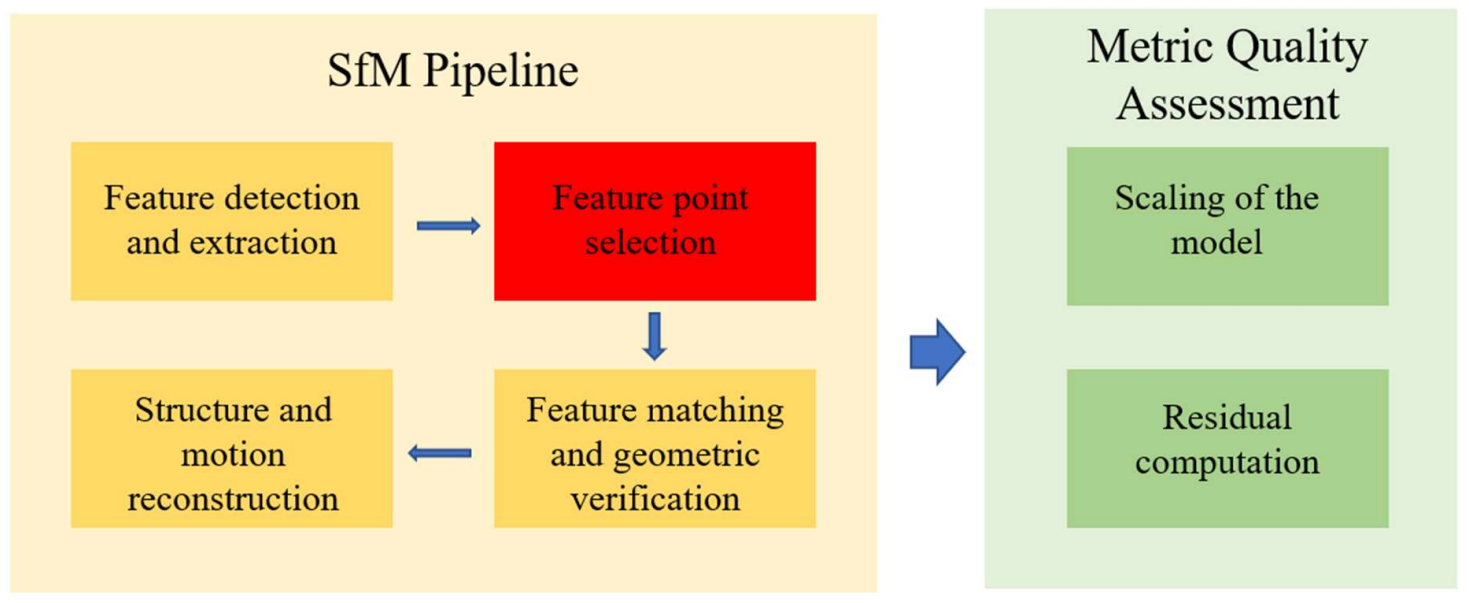

Figure 5. Workflow used for the creation of the 3D representation of the lost structures.

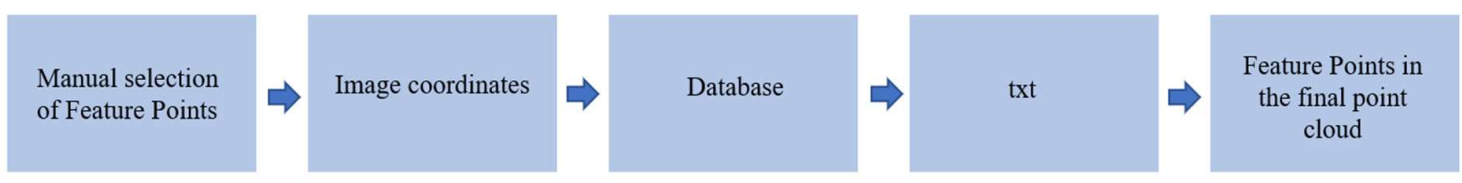

Figure 6. Workflow of the Feature Point selection step of the SfM pipeline. 
- Manual selection of Feature Points and coordinates extraction: the standard "Feature detection and extraction" function of COLMAP automatically detects key points in the images, but it could occur that some important radiometric corners in the image, that appear also in other images, are missing. Introducing this step, it is possible to manually detect the feature points of interest and extract their 3D coordinates (Figure 7)



Figure 7. Feature Point selection during the photogrammetric workflow applied to historical images

- Database: data processed in COLMAP are stored in a customized manageable database. The key points previously selected are stored as row-major float 32 binary blobs (a binary large object consisting of a collection of binary data, stored as a value in the database). The first two columns of the table represent the $\mathrm{x}$ and $\mathrm{y}$ image coordinates, expressed in pixels.

- Txt: New coordinates of Feature Points that are not automatically detected by the algorithm were manually imported in the database, creating a text file (.txt) containing scale and orientation. Following this pipeline, it is possible to import known features (e.g. single points) in the database and use them during the matching stage.

- Results: this assisted processing allows the choice and the filtering of highlight points, such as corners and outline features.

The result of the matching process is a point cloud (Figure 8) that, even if sparse, contains sufficient information for metric evaluation $(670.050$ point, $8,66 \mathrm{MB})$. The presence of some specific known points, selected by the human operator, in fact, allowed the correct scaling of the obtained point cloud.

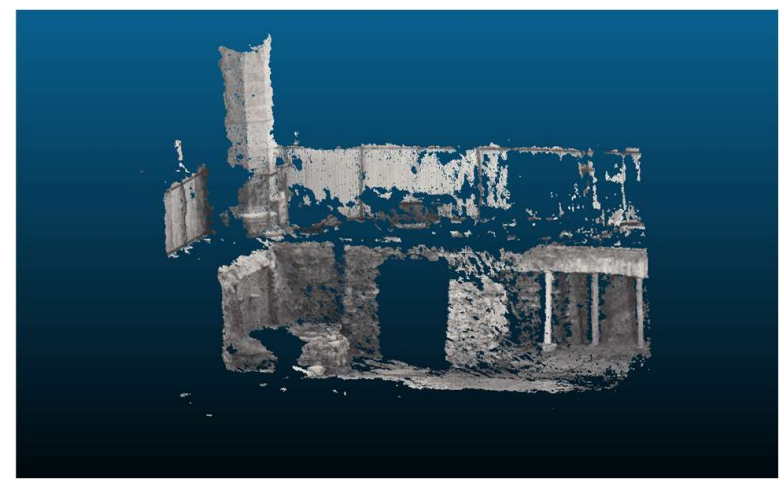

Figure 8. Sparse point cloud obtained with the manual selection of feature points workflow.
In order to scale the point cloud, a pier of the church was used as a reference element. This pier is clearly visible in the historical images, and many points of the photogrammetry point cloud are associated with this element. This pier has been surveyed with LIDAR technology by Prof. Giorgio Verdiani, Architect Alexia Charalambous, and Dr. Giovanni Pescarmona, using the Leica RTC 360 scanner. The point cloud has been cleaned and optimised with Autodesk Recap Pro, and then exported in .pts format. The scaling procedure (Figure 9) has been carried out using CloudCompare, and consisted in the alignment and the scaling of the photogrammetry point cloud (in .txt format) to match the LIDAR reference point cloud.

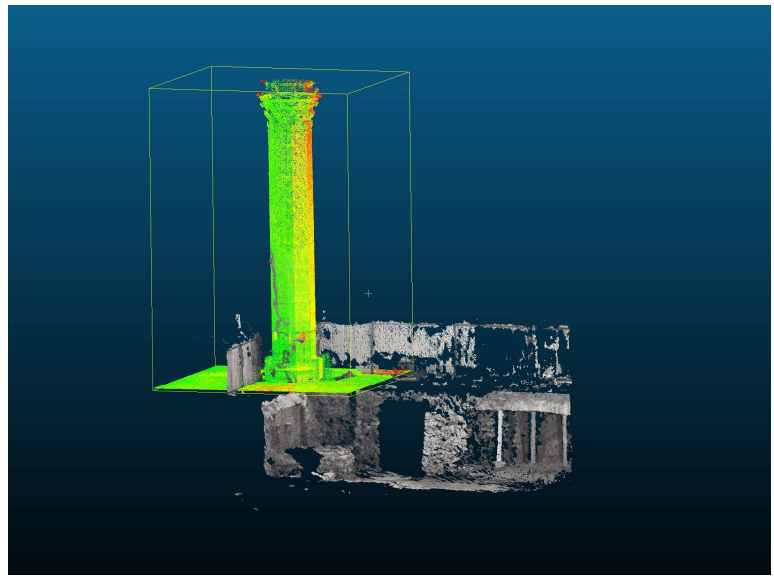

Figure 9. Photogrammetry point cloud (greyscale) scaled to match the reference LIDAR point cloud (gradient).

\section{INTERPRETATION AND VISUALISATION OF THE RESULTS}

Both point clouds have been exported in E.57 format and then re-imported in Recap Pro to be saved as .rcp files. These point clouds have been used as references for retracing using AutoCAD. This operation has been carried out as a critical interpretation step of the obtained data, as the photogrammetry point cloud is very sparse and erratic, and some degree of inference is needed for the vector drawing. Historic images have also been used as visual references, to guide the retracing of those sections where the point cloud was less dense.

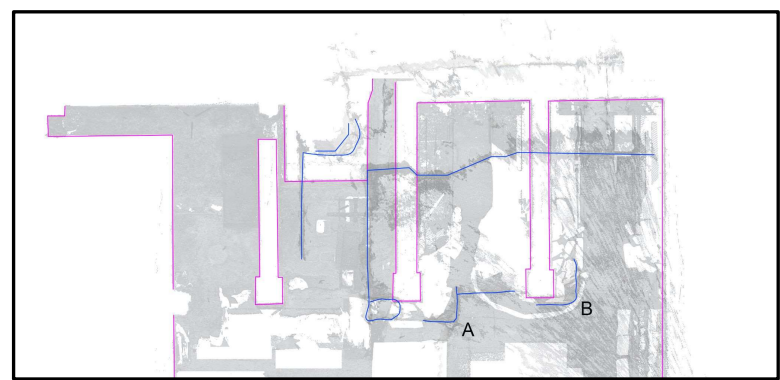

Figure 10. Vector drawing. Purple: underground areas of the basilica (accessible nowadays). Blue: retracing of the SfM point cloud. A and B: foundation pilasters.

The retracing has been made only where the density of the point cloud allowed to follow the edges of the architectures. Three survey drawings made by the Soprintendenza in the ' $60 \mathrm{~s}$ 
have been retraced in CAD as well, in order to allow for the comparison of the different position of the plan of the foundations pilasters. The results are shown in the image below:

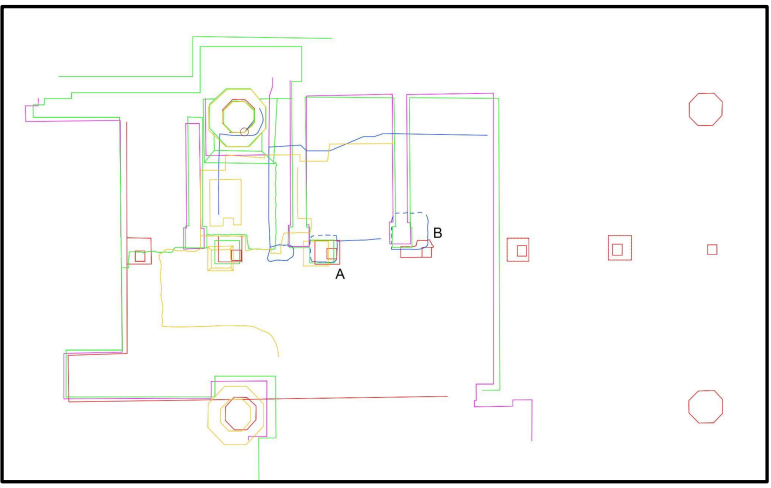

Figure 11. Vector drawing. Yellow, Green, Red: retracing of historical drawings by the Soprintendenza. Purple and blue: same as Figure 10.

In Figure 11, foundation pilaster drawings (A and B) are completed by dashed segments, which represent the likely completion of the portion of the structures that were not visible in the b/w photographs and that, therefore, were not represented in the SfM point cloud.

The different vector drawings obtained by the retracing of the point clouds have been placed in separate layers in CAD and compared. The position of the foundations derived from Soprintendenza drawings and those derived from the SfM point cloud show a significant overlap.

A visual scheme has been proposed to visualise the reliability of data and to represent visually the uncertainty that is associated with the reconstruction work. The more saturated the color, the more likely it is to find the foundation pilaster in that place on the plan. The two pilasters that can be found in the SfM point cloud (A and B) are represented in green, while lateral pilaster (to the left of A) is represented in red. The areas where the color is opaque are associated with a greater overlap.

This process has been carried out following the guidelines of the London Charter for the computer-based visualisation of the cultural heritage (2009), trying to convey within the model the complexity that is associated with scholarly outputs.

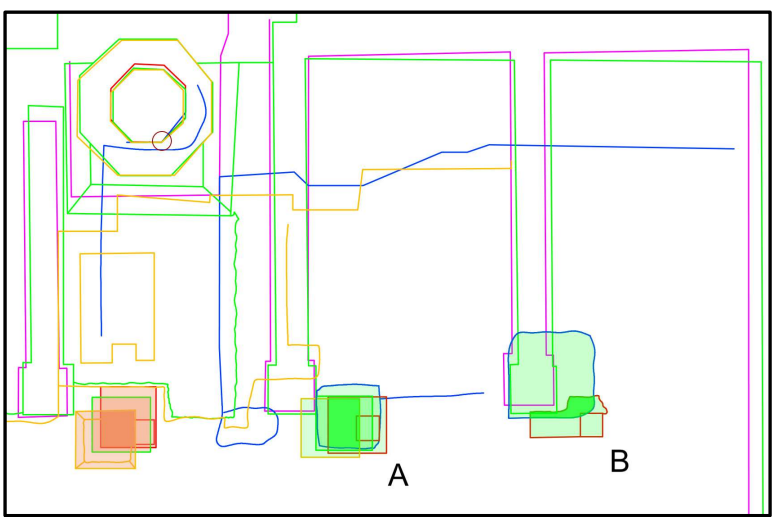

Figure 12. Vector drawing showing the overlapping position of the pilasters.
Retracing the point clouds allows for a clearer and more accurate metric assessment of the pilaster bases. The following diagram (Table 1) compares the measurements taken from the vector drawings of archival material and of the SfM point cloud:

\begin{tabular}{|l|l|l|l|l|l|}
\hline \multicolumn{2}{|c|}{} & $\begin{array}{l}\text { Dwg 1 } \\
\text { (yellow) } \\
\text { [cm] }\end{array}$ & $\begin{array}{l}\text { Dwg 2 } \\
\text { (green) } \\
{[\mathrm{cm}]}\end{array}$ & $\begin{array}{l}\text { Dwg 3 } \\
\text { (red) } \\
\text { [cm] }\end{array}$ & $\begin{array}{l}\text { SfM } \\
\text { Point } \\
\text { Cloud } \\
\text { [cm }]\end{array}$ \\
\hline $\begin{array}{l}\text { Foundation } \\
\text { Pilaster A }\end{array}$ & Width & 110,06 & 106,25 & 110,00 & 119,61 \\
\cline { 2 - 6 } & Depth & 110,37 & 101,69 & 105,00 & 121,01 \\
\hline $\begin{array}{l}\text { Foundation } \\
\text { Pilaster B }\end{array}$ & Width & & & 144,66 & 160,89 \\
\cline { 2 - 6 } & Depth & & & 77.14 & 163,27 \\
\hline
\end{tabular}

Table 1. Measurements of the plan of the foundation pilasters A and $\mathrm{B}$, expressed in centimetres.

The point cloud could not be retraced from a front view, because from this perspective the points are too sparse and erratic. However, measures have been taken from the level of the floor of the underground area to the top of the foundation pilasters visible in the point cloud, in order to understand the original elevation of these groundworks, which must have extended to the height of the floor level of the basilica. Pilaster A is approximately $109 \mathrm{~cm}$ high (showing greater signs of damage), while pilaster B is approximately $239 \mathrm{~cm}$ high.

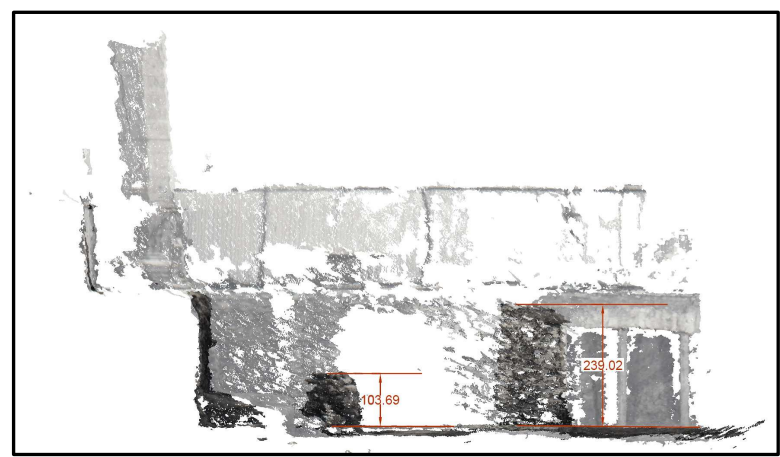

Figure 13. Height measurements of foundation pilasters in the SfM point cloud.

Combining vector drawings of historical survey material with the results obtained by the photogrammetry workflow using historical images it has been possible to create a probability distribution map of the position of the pilasters. These results will be implemented in the research process of the reconstruction of the tramezzo in Santa Croce, providing information that was not available to previous generations of scholars.

As a final step, the point clouds have been optimised for Virtual Reality visualisation (Cioli, Ricci, 2020). The aim of this operation is to disseminate the research results through an immersive interactive technology - such as VR - capable of engaging not only scholars, but also, potentially, enthusiasts and tourists. The virtual visualisation will also play the crucial role of 
helping researchers to grasp the quality and the characteristics of the point cloud, thus acting as a fundamental tool for further studies. Point clouds have been directly imported in UE4, allowing for a more detailed visualization of the collected datasets.

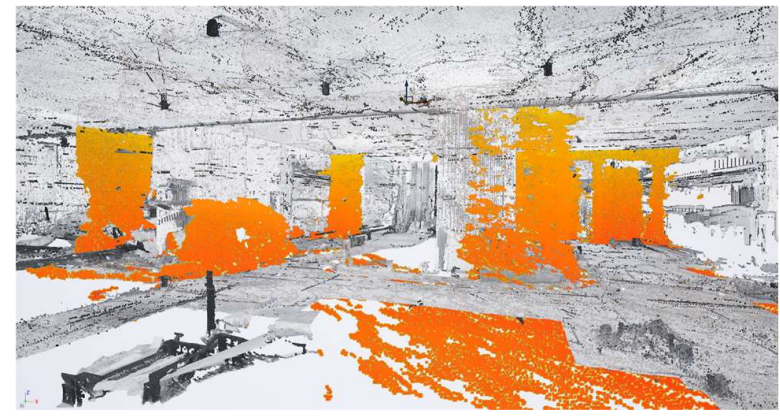

Figure 14. Virtual visualisation of the point clouds within Unreal Engine 4. Orange gradient: SfM; Greyscale: LIDAR

\section{CONCLUSIONS}

Using advanced photogrammetric techniques, and combining them with LIDAR scanning and the analysis of archival material, it is possible to uncover new datasets that were previously inaccessible for scholars, opening new paths of research. This interdisciplinary approach, combining traditional art-historical research methods and state-of-the-art computational tools, tries to bridge the gap between two areas of research that still do not communicate enough with each other, defining new frameworks in the field of Digital Art History.

\section{REFERENCES}

Cioli F., Ricci Y., 2020. L’Officina Profumo-Farmaceutica di Santa Maria Novella. From the Point Cloud to the Virtual Reality. 10.3280/oa-548.107.

COLMAP, Johannes L. Schoenberger, 2019. COLMAP Structure-From-Motion and Multi-View Stereo. https://github.com/colmap/colmap (April 2021).

Condorelli, F., Higuchi, R., Nasu, S., Rinaudo, F., and Sugawara, H., 2019. Improving performance of feature extraction in SfM algorithms for 3D sparse point cloud. Int. Arch. Photogramm. Remote Sens. Spatial Inf. Sci., XLII-2/W17, pp. 101-106, https://doi.org/10.5194/isprs-archives-XLII-2-W17-101-2019, 2019.

De Marchi, A., 2011. Relitti di un naufragio: affreschi di Giotto, Taddeo Gaddi e Maso di Banco nelle navate di Santa Croce. In: Santa Croce oltre le apparenze, edited by De Marchi, A., and Piraz, G., 2011, pp. 33-71.

Farella, E. M., Torresani, A., and Remondino, F., 2019. Sparse point cloud filtering based on covariance features. In: Int. Arch. Photogramm. Remote Sens. Spatial Inf. Sci., Vol. XLII-2/W15, pp. 465-472, https://doi.org/10.5194/isprs-archives-XLII-2W15-465-2019.

Hall, M. B., 1974. The "Tramezzo" in Santa Croce, Florence, Reconstructed, in "The Art Bulletin", LVI, 1974, pp. 325-341.
Hall, M. B., 1979. Renovation and Counter-Reformation. Vasari and Duke Cosimo in Sta Maria Novella and Sta Croce, 15651577, Oxford 1979.

Hu, C., Pan, Z., Li, P., 2019. A 3D Point Cloud Filtering Method for Leaves Based on Manifold Distance and Normal Estimation. In: Remote Sens, Vol. 11, pp. 198-118, https://doi.org/10.3390/rs11020198.

Pescarmona, G.: Technology and religious architecture: a virtual reconstruction of the tramezzo at Santa Croce in Florence. In: ArCo Conference. Art Collections. Cultural Heritage, Safety and Innovation. International Conference proceedings (Sept 21st23rd 2020), University of Florence, Department of Architecture (forthcoming).

Schönberger, J. L. and Frahm, J. M., 2016: Structure-frommotion revisited. In: IEEE Conference on Computer Vision and Pattern Recognition, CVPR 2016, Vol. 2016, pp. 4104-4113.

Tazir, M., Gokhool, T., Checchin, P., Malaterre, L., Trassoudaine, L., 2018. CICP: Cluster Iterative Closest Point for sparse-dense point cloud registration. In: Robotics and Autonomous Systems, Vol. 108, pp 66-86, doi.org/10.1016/j.robot.2018.07.003.

The London Charter for the computer-based visualisation of cultural heritage, 2009. https://www.londoncharter.org/.

Verdiani, G., 2017. Retroprogettazione. Metodologie ed esperienze di ricostruzione 3D digitale per il Patrimonio Costruito. Firenze, 2017

Wang, J., Xu, K., Liu, L., Cao, J., Liu, S., UW-Milwaukee, Z., $\mathrm{Gu}, \mathrm{X}$., 2013. Consolidation of low-quality point clouds from outdoor scenes. In: Proceeding SGP '13. Proceedings of the Eleventh Eurographics/ACMSIGGRAPH Symposium on Geometry Processing, pp. 2017-2016. 